\title{
Modified nodal stage of esophageal cancer based on the evaluation of the hazard rate of the negative and positive lymph node
}

\author{
Jinling Zhang ${ }^{1 \dagger}$, Hongyan $\mathrm{Li}^{2 \dagger}$, Liangjian Zhou', Lianling Yu' ${ }^{1}$, Fengyuan $\mathrm{Che}^{2}$ and Xueyuan Heng ${ }^{1 *}$ (D)
}

\begin{abstract}
Background: The study aimed to propose a modified N stage of esophageal cancer (EC) on the basis of the number of positive lymph node (PLN) and the number of negative lymph node (NLN) simultaneously.

Method: Data from 13,491 patients with EC registered in the SEER database were reviewed. The parameters related to prognosis were investigated using a Cox proportional hazards regression model. A modified $\mathrm{N}$ stage was proposed based on the cut-off number of the re-adjusted ratio of the number of PLN (number PLN) to the number of NLN (numberNLN), which were derived from the comparison of the hazard rate (HR) of number $P L N$ and numberNLN. The modified $\mathrm{N}$ stage was confirmed using the cross-validation method with the training and validation cohort, and it was also compared to the $\mathrm{N}$ stage from the American Joint Committee on Cancer (AJCC) staging system (7th edition) using Receiver Operating Characteristic (ROC) curve analysis.
\end{abstract}

Results: The number PLN on prognosis was 1.042, while numberNLN was 0.968 . The modified N stage was defined as follows: N1 stage: the ratio range was from 0 to 0.21 ; N2 stage: more than 0.21 , but no more than 0.48 ; N3 stage: more than 0.48 . The log-rank test indicated that significant survival differences were confirmed among the N1, N2 and N3 sub-groups of patients in the training population. The difference of all the patients using the modified N stage method were more significant than AJCC N stage. The result of ROC analysis indicated that the modified $\mathrm{N}$ stage could represent the $\mathrm{N}$ stage of EC more accurately.

Conclusion: The modified $\mathrm{N}$ stage based on the re-adjusted ratio of number PLN to numberNLN can evaluate tumor stage more accurately than the traditional $\mathrm{N}$ stage.

Keywords: Esophageal carcinoma, SEER, Tumor metastasis, TNM

\section{Background}

Eesophageal cancer (EC) is a fatal disease with a poor prognosis [1]. Lymph node (LN) metastasis usually occurs in the beginning of diagnosis, and accurate evaluation of the tumor stage is a key step in determining post-operation treatment [2]. However, at present, the definition of $\mathrm{N}$ stage is controversial. The $\mathrm{N}$ stage has

\footnotetext{
*Correspondence: xueyuanheng@yahoo.com

${ }^{\dagger}$ Jinling Zhang and Hongyan Li contributed equally to this work.

${ }^{1}$ Cancer Center of Linyi People's Hospital, Shandong University, School of

Medicine, Linyi 276000, Shandong Province, P. R. China

Full list of author information is available at the end of the article
}

typically been defined by the American Joint Committee on Cancer (AJCC) as the number of positive lymph node (PLN),but a new $\mathrm{N}$ stage was proposed by the Japanese Society for Esophageal Diseases (JSED) [3, 4]. The JSED $\mathrm{N}$ stage is defined according to the site of PLN. The site of PLN has been demonstrated to play an important role in the prognosis of patients with $\mathrm{EC}$, while the key role of number of PLN on the prognosis of patients with EC was repeatedly confirmed and widely received by researchers [5-7]. Furthermore, recent research revealed that the site of PLN was weaker than the number of

(c) The Author(s). 2020 Open Access This article is licensed under a Creative Commons Attribution 4.0 International License, which permits use, sharing, adaptation, distribution and reproduction in any medium or format, as long as you give appropriate credit to the original author(s) and the source, provide a link to the Creative Commons licence, and indicate if changes were made. The images or other third party material in this article are included in the article's Creative Commons licence, unless indicated otherwise in a credit line to the material. If material is not included in the article's Creative Commons licence and your intended use is not permitted by statutory regulation or exceeds the permitted use, you will need to obtain permission directly from the copyright holder. To view a copy of this licence, visit http://creativecommons.org/licenses/by/4.0/ The Creative Commons Public Domain Dedication waiver (http://creativecommons.org/publicdomain/zero/1.0/) applies to the data made available in this article, unless otherwise stated in a credit line to the data. 
PLN (number PLN) in the multiple-parameters analysis using a survival model of EC [8]. Nevertheless, neither of them considered the influence of the number of negative lymph node (NLN) on the prognosis of patients with EC.

Greenstein first proposed the impact of the number of NLN (numberNLN) on the outcome of patients with EC [9]. He suggested that the higher the NLN resected in during surgery would be associated with better postoperative outcome for patients. Hsu confirmed the above identification again in EC [10]. In another study, numberNLN was included in a scoring system for determining the prognosis of EC [11]. In other words, it was accepted that number NLN counted in the operation could increase the accuracy of identifying the N stage of AJCC. It was also inferred that numberNLN could represent site information for tumor metastasis to some extent.

Because of the significant impact number PLN and NLN has on the prognosis of patients with EC, a modified N stage that consists of both PLN and NLN might provide a more accurate representation of the extent of tumor metastasis in the regional LN station. However, it might not be accurate to define the modified $\mathrm{N}$ stage using the ratio of number PLN and NLN directly.

This study investigates the feasibility of a modified $\mathrm{N}$ stage which is based on a combination analysis including the number of positive LN and negative LN in the meantime. The combined analysis refer to the result of the Cox proportional hazard regression model.

\section{Methods}

\section{Data source}

The Surveillance, Epidemiology, and End Results (SEER) program of the National Cancer Institute is a comprehensive source of population-based cancer information in the United States. The SEER database collects disease incidence, patient treatments, and survival data from population-based cancer registries covering around 28\% of the country's population. SEER data comes primarily from hospital medical records as well as records from outpatient surgical, pathology, and radiology centers. The routine data collected in SEER database includes detailed information on demographics, diagnosis, and tumor characteristics. The work team engaged in active follow-up on the cases included in the SEER.

\section{Inclusion criteria for patients}

This study reviewed patient information collected from 2004 to 2011. Data was downloaded using the SEER*Stat software (8.3.5, The Surveillance Research Program of the Division of Cancer Control and Population Sciences, National Cancer Institute.). The inclusion criteria in this study are as follows: 1) All patients should have experienced radical lymphadenectomy; 2) The LN number collected during the operation was clear; 3) EC is one of the specific causes of patient death.

A wide range of patient information was obtained from the SEER database. More specifically, the following variables and covariates were collected for this study: age, gender, tumor size, tumor extension, regional nodes positive, regional nodes negative, race (white, black and other), primary site of tumor (cervical segment, chest segment, abdominal segment and cross-section?), grade classification of tumor (I, II,III, and IV), AJCC Group (I, II,III, and IV), radiation sequence with surgery (no radiation and/or cancer-directed surgery, radiation prior to surgery, radiation after surgery, radiation before and after surgery, surgery both before and after radiation, sequence unknown, but both were given), tumor metastasis to bone, tumor metastasis to brain, tumor metastasis to liver, tumor metastasis to lung, the survival time and the status of patients.

\section{Statistical analysis}

The total population was divided into two groups using a random number table. One group was the training population, and the other was the validation population. The cross-validation method was used between the training population and the validation population.

Cox proportional regression model was used to build a prediction function for time event data. The prediction function including the HR of PLN and NLN provided the coefficient to calculate the re-adjusted number of PLN and NLN for proposing the modified N stage of EC. The cutoff number for the ratio of the PLN count to NLN count was investigated using the method of the minimum of $P$ values. This was performed using the software X-tile (2.0, University of Chicago).

Differences in survival rates between subgroups categorized by $\mathrm{N}$ stage were analyzed using the KaplanMeier analysis and log-rank test. Receiver Operating Characteristic (ROC) Curve Analysis was used to investigate whether the modified $\mathrm{N}$ stage proposed by this study was more effective than the previous $\mathrm{N}$ stage definition.

All analyses were performed using IBM SPSS version 21.0(SPSS Inc. Chicago, Illinois, USA). Continuous variables were presented as the mean \pm standard deviation (SD) or when the data exhibited a skewed distribution, as the median and interquartile range (IQR). $P$ values of 0.05(two-tailed) were established as the threshold for statistical significance.

\section{Results}

Baseline characteristics and outcomes

The data for around 100,000 Patients with EC were reviewed through SEER statistical software, but only the medical records of 13,491 patients were collected under 
the inclusion criteria. The 13,491 patients with EC were classified into two groups according to the random number method. The two groups were the training population $(n=6698)$ and the validation population $(n=$ 6793).

The mean age of the total population was $66.70 \pm$ 11.12 years, and $10,776(79.9 \%)$ of the patients were male. The average tumor size was $366.58 \pm 179.92$. The proportions of white, black, and other races were 84.9, 10.1, $4.7 \%$, respectively. Follow-up data revealed that $5327(39.5 \%)$ of patients survived, and $8164(60.5 \%)$ of patients had died. Average survival time was $11.31 \pm 11.35$ months.

In the comparison of the results from the training population with that from the validation population, no significant differences were observed according to sex, age, tumor site, tumor size, the organ metastasis, number PLN and NLN (Table 1).

\section{The parameters identified in the results of cox proportional Hazard regression analysis}

The univariate analysis revealed that sex, race, age, tumor site, tumor size, tumor length, pathological grade of tumor, AJCC stage, the post-operation treatment, the distance of metastasis, and numberNLN were all independent prognostic factors. The result of the multivariate analysis demonstrated that number PLN was also an independent prognostic factor in addition to the above parameters (Table 2).

\section{The modified $\mathbf{N}$ stage proposed in this study}

According to the results of the Cox proportional hazard model, the HR of PLN was 1.064, and the HR of NLN was 0.962 . The distance between the HR of PLN and the statistical standard point (which was 1) was 0.064 $\left(\triangle \mathrm{HP}_{\text {positive }}\right)$, and the distance between the HR of NLN and the statistical point was $0.038\left(\Delta \mathrm{HP}_{\text {negative }}\right)$. The ratio of $\Delta \mathrm{HP}_{\text {positive }}$ to $\Delta \mathrm{HP}_{\text {negative }}(\mathrm{N}$ ratio) was used as a coefficient to produce the re-adjusted number of PLN and NLN.

The analysis result of the minimum $P$ value method indicated that the following ranges for the modified $\mathrm{N}$ stage were an appropriate solution:

forN0 stage, the re-adjusted $\mathrm{N}$ ratio $=0$;

for N1stage, the re-adjusted $\mathrm{N}$ ratio $=(0-0.08]$;

for N2 stage, the range of rate was $(0.08-0.63]$;

for $\mathrm{N} 3$, the re-adjusted $\mathrm{N}$ ratio $(0.63,+\infty]$

In order to calculate the ratio of the re-adjusted number of PLN to NLN in special situations, the authors settled on the following two definitions of the ratio:
Table 1 Baseline Characteristics of Subjects in the Training and Validation Data

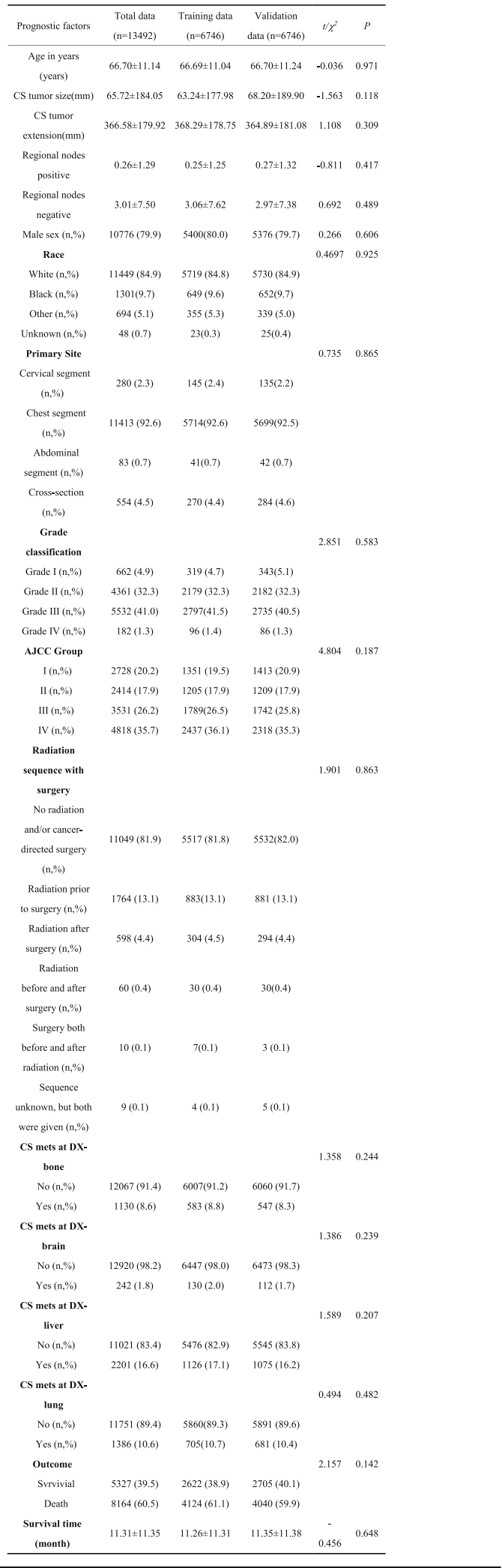


Table 2 Univariate and multivariate for overall survival: Cox proportional hazard regression model

\begin{tabular}{|c|c|c|c|}
\hline Prognostic factors & $\begin{array}{l}\mathrm{p} \text { value } \\
\text { (univariate) }\end{array}$ & $\begin{array}{l}\mathrm{p} \text { value } \\
\text { (multivariate) }\end{array}$ & $\begin{array}{l}\mathrm{HR} \\
(95 \% \mathrm{CI})\end{array}$ \\
\hline CS extension(continuous) & 0.000 & 0.000 & $1.001(1.001 \sim 1.002)$ \\
\hline Regional nodes positive(continuous) & 0.005 & 0.000 & $1.064(1.036 \sim 1.094)$ \\
\hline Regional nodes negative(continuous) & 0.000 & 0.000 & $0.962(0.955 \sim 0.970)$ \\
\hline Grade(I, II, III,IV) & 0.000 & 0.000 & $1.276(1.193 \sim 1.364)$ \\
\hline AJCC Group(I, II, III,IV) & 0.000 & 0.000 & $1.225(1.159 \sim 1.284)$ \\
\hline Radiation sequence with surgery & 0.000 & 0.000 & \\
\hline $\begin{array}{l}\text { Sequence unknown, but both were } \\
\text { given }\end{array}$ & & & 1.000 \\
\hline $\begin{array}{l}\text { No radiation and/or cancer-directed } \\
\text { surgery }\end{array}$ & & & $1.880(0.264 \sim 13.360)$ \\
\hline Radiation prior to surgery & & & $0.990(0.525 \sim 0.897)$ \\
\hline Radiation after surgery & & & $0.813(0.139 \sim 7.069)$ \\
\hline Radiation before and after surgery & & & $1.203(0.167 \sim 8.645)$ \\
\hline $\begin{array}{l}\text { Surgery both before and after } \\
\text { radiation }\end{array}$ & & & $1.355(0.175 \sim 21.798)$ \\
\hline CS mets at DX-bone & 0.000 & 0.000 & \\
\hline No & & & 1.000 \\
\hline Yes & & & $1.506(1.283 \sim 1.767)$ \\
\hline CS mets at DX-brain & 0.000 & 0.000 & \\
\hline No & & & 1.000 \\
\hline Yes & & & $1.422(1.013 \sim 1.997)$ \\
\hline CS mets at DX- liver & 0.000 & 0.000 & \\
\hline No & & & 1.000 \\
\hline Yes & & & $1.357(1.187 \sim 1.552)$ \\
\hline CS mets at DX-lung & 0.000 & 0.000 & \\
\hline No & & & 1.000 \\
\hline Yes & & & $1.405(1.206 \sim 1.636)$ \\
\hline
\end{tabular}


1 When number PLN and NLN were both 0 , the ratio of the readjusted number of PLN to NLN (readjusted $\mathrm{N}$ ratio) was defined as 0 ;

2 When one of numberPLN and numberNLN is 0,0 was defined as 0.0001 .

The feasibility and superiority of the modified $\mathrm{N}$ stage A cross-validation study was performed on the modified $\mathrm{N}$ stage. The modified $\mathrm{N}$ stage was developed from the training population and validated using the validation population. The log-rank test indicated that significant survival differences were confirmed among the N1, N2 and N3 sub-groups of patients in the training population, and the survival difference could be replicated in the validation population using the Kaplan-Meier analysis $(P<0.05$, Fig. 1$)$.

The log-rank test indicated that significant survival differences were confirmed among the N1, N2 and N3 subgroups of all patients, and the difference of all the patients using the modified $\mathrm{N}$ stage method were more significant than AJCC N stage (Fig. 2).

The result of ROC analysis revealed that the area under AJCC N stage curve was 0.934, and the area under modified N stage curve was 0.956 , which indicated that
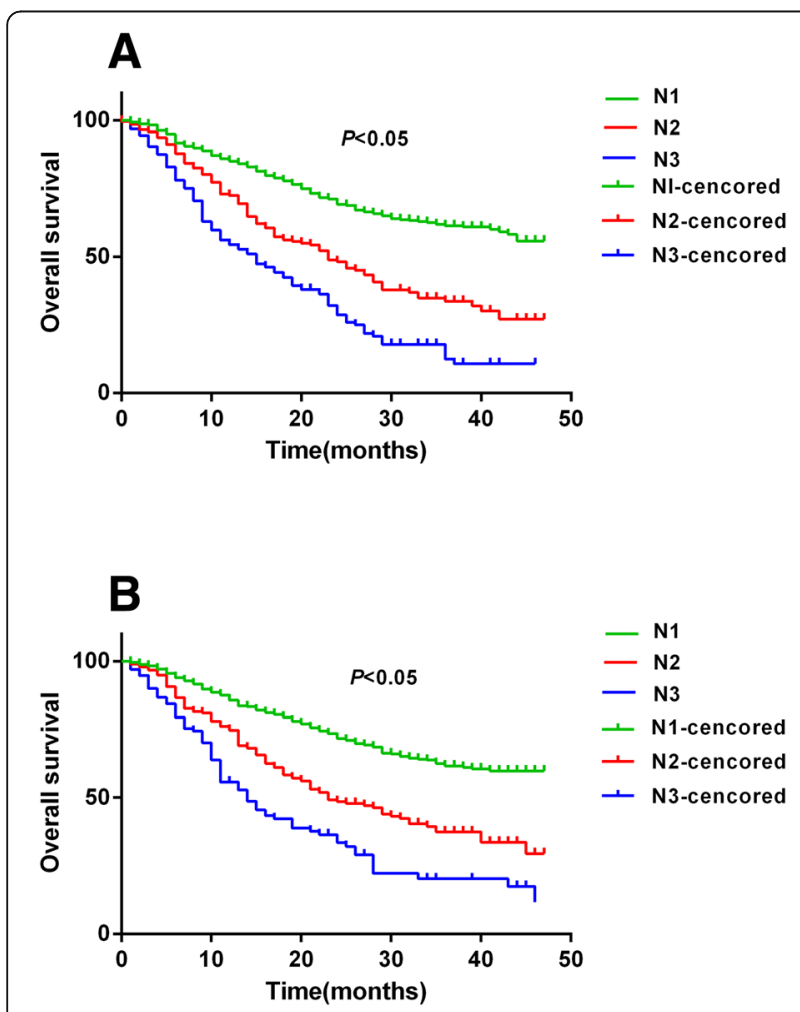

Fig. 1 The comparison of overall survival between training group and validation group. a The survival difference among N1, N2 and N3 sub group in training data were significant $(P<0.05)$. b The survival difference among N1, N2 and N3 sub group in validation data were significant $(P<0.05)$

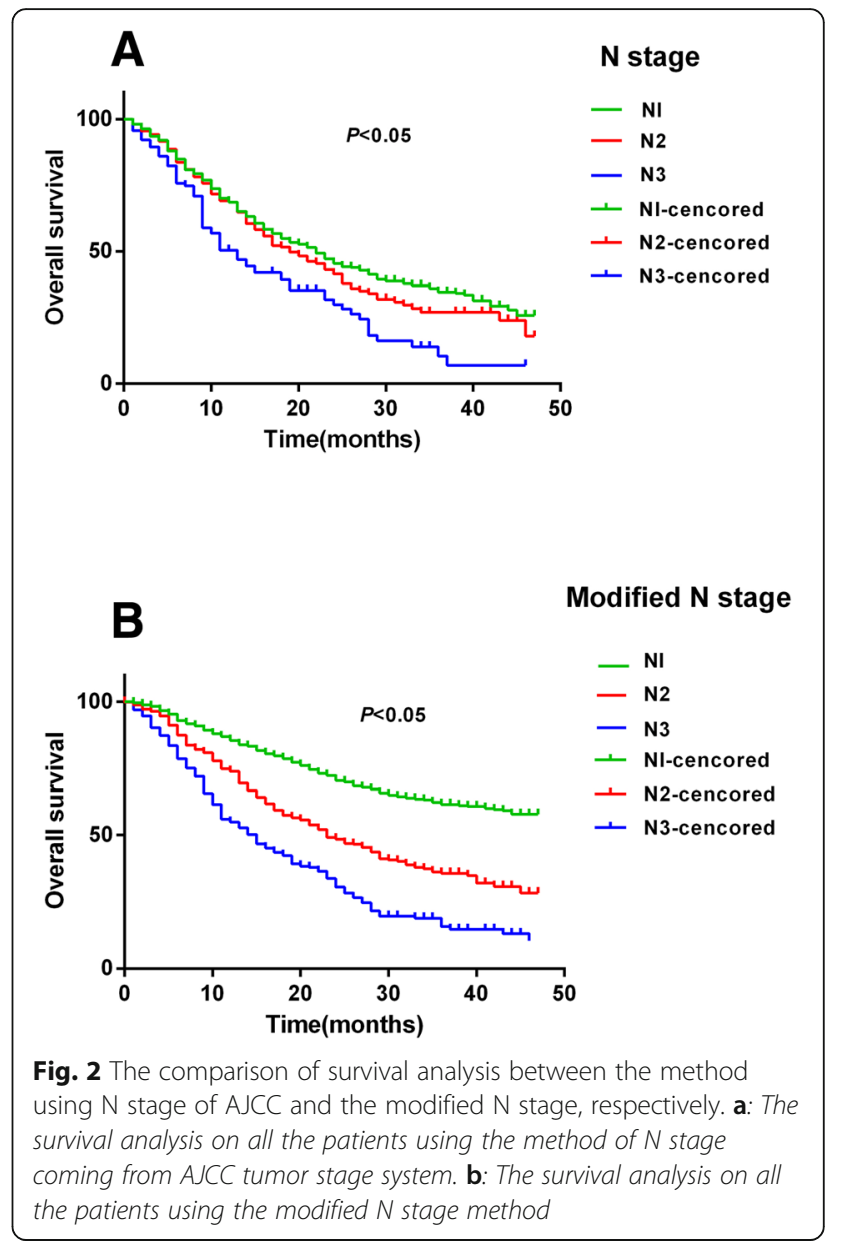

the modified $\mathrm{N}$ stage could represent the $\mathrm{N}$ stage of $\mathrm{EC}$ more accurately (Fig. 3).

\section{Discussion}

Because the parameters of the tumor metastasis site may not be stable, patients with EC might be not benefit from the extensive lymphadenectomy $[12,13]$. The site would very likely be affected by the extent of operation, whereas number PLN collected in lymphadenectomy would not be. Because the PLN was usually enlarged, the surgeon was likely to notice it during lymphadenectomy and would remove it. This means numberPLN would remain stable regardless of the individual extent of lymphadenectomy and the practice of different surgeons.

Research has indicated that the NLN number could represent the extent of lymphadenectomy in patients with EC, therefore, more NLN removed meant a better prognosis [14]. However, it was controversial how many NLN should be removed in the lymphadenectomy to achieve a better prognosis. Greenstein advised that 18 NLN should be removed in the lymphadenectomy to obtain a better outcome for patients with EC, while 19 NLN was suggested by another study [9, 10]. Baba 

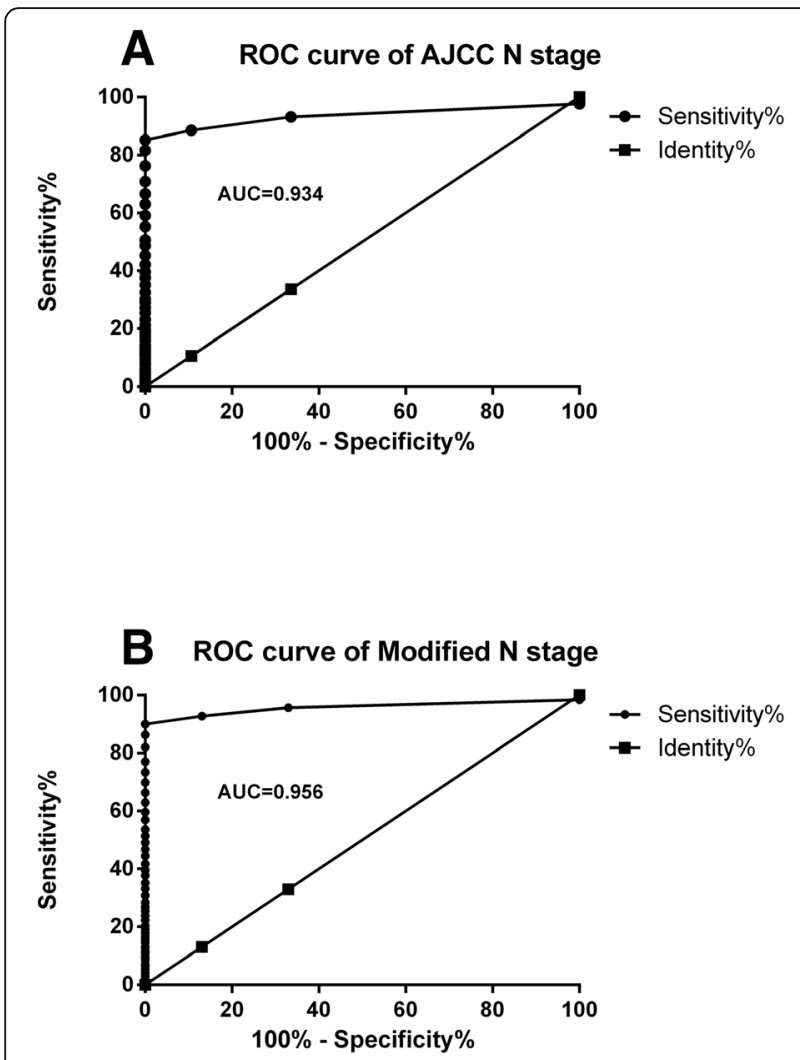

Fig. 3 The ROC analysis on the AJCC N stage and modified N stage. The result of $R O C$ analysis revealed that the area under AJCC $N$ stage curve was 0.934, the area under modified N stage curve was 0.956

suggested that 31 NLN should be resected at least in the lymphadenectomy, however, this study found that 31 NLN should be resected only on patients who experienced the three-field dissection for the lymphadenectomy [15]. This finding indicated that numberNLN was an important factor in the prognosis of patients with EC.

However, the result of the above studies on the advised resected number of NLN was slightly different. The reason for this might be that numberNLN was easily influenced by the confounders than others. Although number NLN could indicate the extent of lymphadenectomy and could reflect the site of tumor metastasis to some extent, a stable cut-off number of NLN removed in lymphadenectomy indicating a better prognosis were not replicated in this study.

The ratio of number PLN to numberNLN or the ratio of number PLN to the total number of LN removed in lymphadenectomy could be used to explore the cut-off number which differentiates patients into sub groups with different outcome. This cut-off number could be used for proposing the modified $\mathrm{N}$ stage. Dhar et al first reported the ratio of numberPLN to the total number of LN as a prognostic factor in EC in 2000 [16]. Mariette et al showed that the ratio of number PLN to the total number of LN was a strong independent prognosis factor [17]. The above studies demonstrated that the ratio number PLN to the total number of LN was as important as number PLN regardless of the extent of the lymphadenectomy and the application of neoadjuvant chemoradiation. However, what the best cut-off number was for the ratio of numberPLN to the total number of $L N$ remained controversial. Several studies proposed 0.2 as the cut-off number for the ratio in their modified $\mathrm{N}$ stage regimens, while other studies concluded that the cut-off number for the ratio should be 0.3 [18-21]. In the meantime, Tan suggested that 0.25 might be a more appropriate cut-off number for the ratio than 0.35 , which was identified in Shao's research $[22,23]$. The above results indicated that the ratio of number PLN to the total number of LN failed to consistently predict the prognosis for patients with EC. The reason might be that none of the above research compared the relative impact of PLN, NLN, and total LN removed in lymphadenectomy on the general prognosis, but they simply used the ratio between them to explore the modified $\mathrm{N}$ stage. The criterion of the above-modified $\mathrm{N}$ stage would be affected by the research cohort or the proportion of patients.

This study proposed the cut-off ratio of the PLN count to the NLN count based on the results of the Cox proportional hazard model. The procedure in this study was more reasonable than those procedures which directly explored the ratio of the PLN count to the NLN count. Furthermore, the cut-off ratio proposed in this study has been further confirmed using the cross-validation method on cohort data from the SEER database.

The N stage introduced by the 7th AJCC was a regular criterion. The priority of its in predicting prognoses was usually selected to be compared by procedures of modified $\mathrm{N}$ stage recently.

A cross-validation study was performed on the modified $\mathrm{N}$ stage. The modified $\mathrm{N}$ stage was developed from the training population and validated using the validation population, and the survival difference could be replicated in the validation population using the KaplanMeier analysis, and the difference of all the patients using the modified $\mathrm{N}$ stage method were more significant than AJCC $\mathrm{N}$ stage. The survival analysis in this study confirmed that the survival line of subgroups from the modified $\mathrm{N}$ stage separated more significantly than that of the N stage of 7th AJCC. Furthermore, the comparison between the modified $\mathrm{N}$ stage and the AJCC N stage was performed using the ROC method. The result of the ROC curve analysis demonstrated the superiority of this modified $\mathrm{N}$ stage system, which in turn supported the assumption of this study: the relative impact of PLN and NLN on the prognosis based on the results of the Cox proportional hazard model should be considered in the modified $\mathrm{N}$ stage. 
It was widely accepted that tumor differentiation, number PLN and NLN, the tumor stage of 7th AJCC, and organ metastasis were all independent prognostic factors [24, 25]. This study confirmed that finding. Studies also showed that the age of patients was also a prognostic factor [26, 27]. This study confirmed the finding as well. However, based on the analysis result of the Cox proportional hazard model, age only had a small impact on a patient's prognosis. This result implied that the impact of age on prognosis would only be noticed when using a big cohort. This finding was consistent with our previous research [28].

A recent report revealed that Patients with EC with organ metastasis or distant metastasis in bone had the worst prognosis than others [5]. In this study, patients with tumor metastasis in bone had a worse outcome than those with tumor metastasis in the lungs or liver, but had a better outcome than patients with tumor metastasis in the brain. This finding was consistent with the report which showed that brain metastatic tumors with a primary tumor located in the esophagus only had a mean survival time of six months [29].

Although the current study proposed a reasonable modified $\mathrm{N}$ stage for EC, it has several limitations. First, the study was retrospective; its results may be affected by confounding factors that were not controlled for. Second, although the SEER database was prepared according to strict criteria, the data was collected from multiple research centers with different operational habits. As a result, some differences in findings may be due to differences in research center practices. Third, the sample in this study consisted of different pathological types of EC. Because the data did not include which type of EC, this study could not determine whether there was a difference between the application of this modified $\mathrm{N}$ stage system or in the ESCC and SCC sub-cohorts.

In summary, based on the results of the Cox proportional hazard model, the study proposed a modified $\mathrm{N}$ stage derive from the $\mathrm{N}$ stage system of 7 th AJCC for EC. The study also identified the reasonability and superiority of the modified $\mathrm{N}$ stage using the crossvalidation method comp -arising to the $\mathrm{N}$ stage system of 7th AJCC. This modified N stage system is a promising step toward more accurately identifying the $\mathrm{N}$ stage of EC and in turn, providing more effective treatment for this devastating disease.

\section{Conclusions}

The modified $\mathrm{N}$ stage based on the re-adjusted ratio of number PLN to numberNLN can evaluate tumor stage more accurately than the traditional $\mathrm{N}$ stage.

\section{Abbreviations}

EC: Esophageal cancer; LN: Lymph node; PLN: Positive lymph nodes; NLN: Negative lymph nodes; ESCC: Esophageal squamous cell carcinoma; HR: Hazard ratio; ROC: Receiver Operating Characteristic; LNM: Lymph node metastasis; AJCC: American Joint Committee on Cancer; SD: Standard deviation; IQR: Interquartile range; SEER: Surveillance, Epidemiology, and End Results; JSED: Japanese Society for Esophageal Diseases

\section{Acknowledgments \\ Thanks are expressed to the participants for their contributions to the study.}

\section{Authors' contributions}

$J L Z$ : conceived, design the study, and write the paper. HY L: analysized the data and write the paper. $L J Z$ : assist in the research. $L L Y$ : assist in the research. FY C: assist in the research. $\mathrm{XY} \mathrm{H}$ : overall command the research. All authors have read and approved the manuscript.

\section{Funding}

This study was supported by Shandong Provincial Medical and Health Development plan (2013WSA13018), Natural Science Foundation of Shandong Province (ZR2014HL062). The funding body had no role in the design of the study and collection, analysis, and interpretation of data and in writing the manuscript.

\section{Availability of data and materials}

The data sets supporting the results of this article are included within the article.

Ethics approval and consent to participate

Because the data was collected from the Surveillance, Epidemiology, and End Results (SEER), database, therefore it doesn't involve ethical approval and consent to participate.

Consent for publication

Not applicable.

\section{Competing interests}

We declare that we do not have any commercial or associative interest that represents a conflict of interest in connection with the work submitted.

\section{Author details}

${ }^{1}$ Cancer Center of Linyi People's Hospital, Shandong University, School of Medicine, Linyi 276000, Shandong Province, P. R. China. ${ }^{2}$ Department of Central Laboratory, Linyi People's hospital, Shandong University, School of medicine, Linyi 276000Shandong ProvinceP. R. China.

Received: 5 August 2020 Accepted: 18 November 2020

Published online: 07 December 2020

\section{References}

1. Sohda M, Kuwano H. Current Status and Future prospects for esophageal Cancer treatment. Ann Thoracic Cardiovasc Surg. 2017;23:1-11.

2. Rice TW, et al. Esophageal Cancer: associations with $(\mathrm{pN}+)$ lymph node metastases. Ann Surg. 2017;265:122-9.

3. Kajiyama Y. New Japanese classification of esophageal Cancer (11th edition) Gan To Kagaku Ryoho. 2016;43:1049-52.

4. Oweira $\mathrm{H}$, et al. Validation of the eighth clinical American joint committee on Cancer stage grouping for esophageal cancer. Future Oncol. 2018;14:6575.

5. Wu SG, et al. Sites of metastasis and overall survival in esophageal cancer: a population-based study. Cancer Manage Res. 2017:9:781-8.

6. Chen J, et al. A new clinical staging system for esophageal cancer to predict survival after definitive chemoradiation or radiotherapy. Diseases of the esophagus: official journal of the international society for. Dis Esophagus. 2018;31(11):1-9.

7. Rice TW, et al. Recommendations for clinical staging (CTNM) of cancer of the esophagus and esophagogastric junction for the 8th edition AJCC/ UICC staging manuals. Dis Esophagus. 2016;29:913-9.

8. Kunisaki C, et al. Impact of lymph-node metastasis site in patients with thoracic esophageal cancer. J Surg Oncol. 2010;101:36-42.

9. Greenstein AJ, et al. Effect of the number of lymph nodes sampled on postoperative survival of lymph node-negative esophageal cancer. Cancer. 2008;112(6):1239-46. 
10. Hsu PK, et al. The prognostic value of the number of negative lymph nodes in esophageal cancer patients after transthoracic resection. Ann Thorac Surg. 2013;96(3):995-1001.

11. Ma G, et al. A novel multivariate scoring system for determining the prognosis of lymph node-negative esophageal squamous cell carcinoma following surgical therapy: an observational study. Eur J Surg Oncol. 2015; 41(4):541-7.

12. Hagens ERC, et al. The extent of lymphadenectomy in esophageal resection for cancer should be standardized. J Thorac Dis. 2017;9(\$8):S713.

13. Phillips AW, et al. Impact of extent of lymphadenectomy on survival, post Neoadjuvant chemotherapy and transthoracic Esophagectomy. Ann Surg. 2017;265(4):750-6.

14. Yang $\mathrm{HX}$, et al. An evaluation of the number of lymph nodes examined and survival for node-negative esophageal carcinoma: data from China. Ann Surg Oncol. 2010;17(7):1901-11.

15. Baba $Y$, et al. Negative lymph-node count is associated with survival in patients with resected esophageal squamous cell carcinoma. Surgery. 2013; 153(2):234-41.

16. Dhar DK, et al. Appraisal of a revised lymph node classification system for esophageal squamous cell cancer. Ann Thorac Surg. 2007;83(4):1265-72.

17. Mariette $C$, et al. The number of metastatic lymph nodes and the ratio between metastatic and examined lymph nodes are independent prognostic factors in esophageal cancer regardless of neoadjuvant chemoradiation or lymphadenectomy extent. Ann Surg. 2008;247(2):365-71.

18. Bhamidipati CM, et al. Pathologic lymph node ratio is a predictor of survival in esophageal cancer. Ann Thorac Surg. 2012:94(5):1643-51.

19. Hsu WH, et al. The metastatic lymph node number and ratio are independent prognostic factors in esophageal cancer. J Gastrointest Surg. 2009;13(11):1913.

20. Feng J, Fau-Huang Y, et al. Prognostic analysis of esophageal cancer in elderly patients: metastatic lymph node ratio versus 2010 AJCC classification by lymph nodes. World J Surg Oncol. 2013;11:162.

21. He Z, et al. Use of the metastatic lymph node ratio to evaluate the prognosis of esophageal cancer patients with node metastasis following radical esophagectomy. PLoS One. 2013;8(9):e73446.

22. Tan Z, et al. Can lymph node ratio replace pn categories in the tumornode-metastasis classification system for esophageal cancer? J Thorac Oncol. 2014;9(8):1214-21.

23. Shao $\mathrm{Y}$, et al. Assessment of lymph node ratio to replace the $\mathrm{pN}$ categories system of classification of the TNM system in esophageal squamous cell carcinoma. Journal of thoracic oncology: official publication of the International Association for the Study of. Lung Cancer. 2016;11(10):177484.

24. Akutsu Y, et al. The prevalence of overall and initial lymph node metastases in clinical T1NO thoracic esophageal Cancer: from the results of JCOG0502, a prospective multicenter study. Ann Surg. 2016;264:1009-15.

25. Talsma K, et al. Impact of Neoadjuvant Chemoradiation on lymph node Status in esophageal Cancer: post hoc analysis of a randomized controlled trial. Ann Surg. 2017;266:e52-e3.

26. Cheng YFA-Ohoo, et al. Esophageal squamous cell carcinoma and prognosis in Taiwan. LID - https://doi.org/10.1002/cam4.1499.

27. Miyata $\mathrm{H}$, et al. Clinical outcome of Esophagectomy in elderly patients with and without Neoadjuvant therapy for thoracic esophageal Cancer. Ann Surg Oncol. 2015;22(3):794-801.

28. Cheng J, et al. Explore the radiotherapeutic clinical target volume delineation for thoracic esophageal squamous cell carcinoma from the pattern of lymphatic metastases. J Thorac Oncol. 2013;8(3):359-65.

29. Rades $D$, et al. Predicting overall survival in patients with brain metastases from esophageal cancer. Anticancer Res. 2014:34(11):6763-5.

\section{Publisher's Note}

Springer Nature remains neutral with regard to jurisdictional claims in published maps and institutional affiliations.

Ready to submit your research? Choose BMC and benefit from:

- fast, convenient online submission

- thorough peer review by experienced researchers in your field

- rapid publication on acceptance

- support for research data, including large and complex data types

- gold Open Access which fosters wider collaboration and increased citations

- maximum visibility for your research: over $100 \mathrm{M}$ website views per year

At $\mathrm{BMC}$, research is always in progress.

Learn more biomedcentral.com/submissions 